\title{
Proactivity Inventory Development for Senior High School Students
}

\author{
Masnurrima Heriansyah ${ }^{1}$ \\ ${ }^{1}$ Universitas Mulawarman
}

\begin{tabular}{l} 
Article Info \\
\hline Article history: \\
Received Aug $05^{\text {th }}, 2019$ \\
Revised Oct $09^{\text {th }}, 2019$ \\
Accepted Jun $17^{\text {th }}, 2020$ \\
\hline
\end{tabular}

Keyword:

Inventory

Development

Proactivity

\begin{abstract}
Understanding of students' attitudes in responding, taking initiative and responsibility is needed by the guidance and counseling teacher so that they can optimally develop themselves. This research aims to produce proactivity inventory for senior high school students. The research subjects were senior high school students in Samarinda. The research design used was mixed method design. Inventory validity was conducted through the stage of expert assessment and item-test correlation using Pearson product-moment correlation coefficient analysis, while reliability was obtained by calculating Alpha coefficient through Cronbach's alpha reliability analysis. The results of research generated 48 inventory items that were used to measure proactivity consisting of aspects of choosing response, ability to take initiative and take responsibility. The research conclusion generated proactivity inventory consisting of 48 items including positive and negative statements. Research implications can help the implementation of guidance and counseling services in senior high school.
\end{abstract}

(C) 2020 The Authors. Published by IICET.

This is an open access article under the CC BY-NC-SA license (https://creativecommons.org/licenses/by-nc-sa/4.0

\section{Corresponding Author:}

Masnurrima Heriansyah, Universitas Mulawarman Email: herijonk@yahoo.com

\section{Introduction}

Pemahaman terhadap kebutuhan siswa dalam layanan bimbingan dan konseling sangat diperlukan untuk dapat menentukan kesesuaian dan ketepatan dalam penyusunan program layanan. Penyusunan program layanan bimbingan dan konseling di mulai dengan melakukan asesmen kebutuhan siswa. Dalam melakukan asesmen diperlukan instrument sehingga dapat mengumpulkan data siswa secara tepat. Berbagai instrumen yang baku dan digunakan saat ini meliputi instrument tes dan non tes. Instrumen tes seperti tes bakat, tes minat dan tes intelegensi dan instrument non tes seperti alat ungkap masalah (AUM) dan inventori tugas perkembangan (ITP). Instrumen yang baku ini sudah memiliki fokus masing-masing sesuai dengan permasalahan atau kebutuhan siswa.

Berdasarkan kebutuhan siswa sekolah diperlukan pengembangan instrumen baru untuk melengkapi aspekaspek yang diperlukan untuk memahami siswa seperti kebutuhan pemahaman terhadap proaktivitas siswa di sekolah menengah atas. kebutuhan ini berdasarkan kondisi yang terjadidi sekolah dan belum tersedia instrumen yang fokus terhadap proaktivitas siswa.

Covey (2010) menjelaskan bahwa proaktivitas adalah kemampuan untuk memiliki kebebasan dalam memilih respon, kemampuan mengambil inisiatif dan kemampuan untuk bertanggung jawab. Proaktivitas perlu dipahami agar siswa dapat berkembang sesuai potensi dirinya. 
Perkembangan pergaulan di kalangan remaja saat ini semakin kompleks memerlukan kekuatan dalam diri siswa untuk mencegah hal-hal yang berbahaya bagi dirinya. Penguatan dalam diri siswa menjadi mutlak harus di lakukan secara terus menerus sehingga perilaku negatif dan beresiko dapat di hindari.

Beberapa masalah yang masih terjadi pada siswa dalam menerapkan sikap proaktivitas seperti 1) Kurang mampu dalam mengambil inisiatif dan lebih senang menunda tugas yang diberikan oleh guru, 2) kemampuan untuk asertif terhadap hal buruk yang mendekatinya 3) kurang tanggung jawab dalam melaksanakan tugas yang diberikan oleh guru, 4) lebih banyak mengeluh terhadap tugas yang diberikan.

Masalah yang masih terjadi perlu di pahami secara mendalam oleh guru oleh sebab itu perlu di kembangkan instrumen pemahaman melalui inventori. Chaplin (2006) menjelaskan inventori adalah suatu alat yang digunakan untuk menaksir dan menilai ada atau tidaknya tingkah laku, minat, sikap tertentu.

Pengembangan inventori diperkuat berdasarkan penelitian sebelumnya yang pernah dilakukan oleh Heriansyah (2017) tentang inventori kepribadian ideal budaya dayak ngaju dalam layanan bimbingan dan konseling. Inventori yang dikembangkan fokus terhadap proaktivitas siswa sekolah menengah atas. Hal ini bertujuan agar proaktivitas siswa di SMA dapat dipahami dan memberikan dampak positif terhadap proses pembelajaran bagi siswa. Proaktivitas yang di kembangkan dalam inventori meliputi aspek kebebasan memilih respon, mengambil inisiatif dan tanggung jawab. Dengan memahami proaktivitas siswa di harapkan guru bimbingan dan konseling atau konselor dapat mengetahui seberapa jauh kekuatan dalam diri siswa untuk dapat di kembangkan sesuai dengan potensi dirinya.

Selain itu pengemabnagn inventori proaktivitas dapat menjadi khasanah dalam melengkapi berbagai instrumen yang sudah tersedia sehingga dapat memberikan pemahaman terhadap kondisi siswa sehingga guru bimbingan dan konseling atau konselor sekolah mampu memberikan layanan yang optimal.

Berbagai hambatan dalam pelaksanaan layanan bimbingan dan konseling di sekolah salah satunya di pengaruhi oleh kurangnya pemahaman terhadap diri siswa. Karakter siswa yang beraneka ragam dan unik membuat kebutuhan mereka sangat kompleks. Kompleksitas kebutuhan siswa mengharuskan ketepatan dalam proses memahami, menganalisis serta intervensi.

Sehingga penelitian ini bertujuan mengembangan inventori proaktivitas bagi siswa sehingga intervensi terhadap diri siswa yang terlihat dari sikap ataupun perilaku dapat di pahami oleh guru bimbingan dan konseling atau konselor secara tepat dan komprehensif.

\section{Method}

Pengembangan inventori proaktivitas bagi siswa sekolah menengah atas menggunakan jenis penelitian mixed methods. Sampel penelitian adalah siswa sekolah menengah atas di Samarinda sebanyak 100 siswa Teknik pengambilan sampel menggunakan purposive sampling. Teknik analisis menggunakan analisis kuantitatif dan kualitatif. Analisis kuantitatif untuk melihat validitas dan reliabilitas sedangkan analisis kualitatif untuk melihat bahasa dan kesulitan siswa dalam memahami setiap item instrumen. Pengembangan inventori proaktivitas mengikuti prosedur pengembangan inventori yang di tulis oleh Azwar (2012) yaitu 1) Identifikasi tujuan ukur, 2) Pembatasan domain ukur, 3) Operasional aspek, 4) Penulisan item, 5) Uji coba bahasa, 6) Field test, 7) Seleksi item, 8) Validasi konstrak, 9) Kompilasi final.

\section{Result and Discussion}

Hasil pengembangan inventori proaktivitas di mulai dengan penyusunan tujuan ukur proaktivitas siswa dengan mengkaji konstrak teoritik tentang proaktivitas selanjutnya di rumuskan aspek-aspek yang akan dikembangkan meliputi aspek memilih respon, inisiatif dan bertanggung jawab.

Aspek-aspek tersebut di operasionalkan dalam bentuk indikator melalui kisi-kisi yang akan review melalui ujicoba ahli. Uji ahli dilakukan kepada 2 orang ahli yang memiliki latar belakang inventori dan proaktivitas untuk melihat kesesuaian dalam aspek, indikator dan item inventori sebagai masukan dalam penyempurnaan inventori. Setelah dilakukan perbaikan di dapatkan blue print inventori. Dilanjutkan uji coba kepada siswa sebanyak 100 orang untuk melihat keterbacaan inventori meliputi pemahaman siswa tentang inventori, bahasa dan pernyataan setiap item inventori.

Setelah hasil uji coba di dapat gambaran inventori dari kelompok pengguna setelah itu dilakukan seleksi item, validasi konstrak dan kompilasi final inventori. Kompilasi final item inventori menghasilkan sebanyak 48 item yang valid dan reliabel yang meliputi 26 item pernyataan positif dan 22 item pernyataan yang negatif. 
Pengembangan inventori proaktivitas menghasilkan validitas yang baik dengan 0,66 sedangkan uji reliabilitas sebesar 0,887. Berikut di jelaskan dalam bentuk tabel.

Tabel 1. Uji Reliabilitas Pengembangan Inventori Proaktivitas Siswa Sekolah Menengah Atas

\begin{tabular}{ccc}
\hline Komponen & Koefisien Reliabilitas & Jumlah item \\
\hline Uji kelompok kecil & 0,887 & 48 \\
\hline
\end{tabular}

Pengembangan inventori proaktivitas memberikan gambaran terhadap diri siswa dalam tiga aspek yaitu aspek memilih respon, inisiatif dan tanggung jawab. Aspek memilih respon menggambarkan siswa tentang pandangan mereka tentang kesadaran diri. Kekuatan terbesar dalam diri individu adalah kesadaran diri indikator meliptui kemampuan memahami dan menilai dirinya, dengan kemmampuan memahami diri dan menilai diri seseorang akan sadar apa yang harus dilakukannya. Mengetahui pandangan diri tentang baik dan buruk sehingga mampu memfilter diri dari pengaruh negatif lingkungan.

Aspek inisiatif memberikan gambaran siswa tentang kemampuan mereka mengembangkan kreativitas dan imajinasi mereka dalam kehidupan pribadi maupun belajar mereka sehingga aktivitas keseharian mereka mampu memberikan dampak positif dalam pengembangan diri dan kekuatan diri.

Aspek tanggung jawab memberikan gambaran tentang kesiapan siswa menghadapi berbagai tugas dan konsekuensi dari proses belajar mereka dan apa yang harus dilakukan mereka dalam lingkungan kehidupan mereka. Pengembangan inventori menghasilkan 48 item yang final dan valid, inventori proaktivitas dapat digunakan dalam mengukur dan memahami proaktivitas siswa. Pengembangan inventori proaktivitas menghasilkan buku tes dan lembar jawaban. Buku tes terdiri atas pengantar inventori, komposisi, petunjuk penggunaan, langkah penilaian, skor penilalian dan kategori.

Penelitian ini juga diperkuat oleh penelitian sebelumnya yaitu penelitian Susanto dan Mudaim (2017) tentang Pengembangan inventori MBTI sebagai alternatif instrumen pengukuran tipe kepribadian dan penelitian Yulinawati1, Bariyyah dan Permatasari (2018) tentang Pengembangan inventori stres akademik siswa sekolah menengah pertama (SMP) Negeri Kota Malang serta penelitian Marlina, Ahmad dan Pandang (2015) tentang Pengembangan inventori peminatan karir (IPK) sebagai alat ukur arah pilih karir siswa

Penelitian terdahulu memberikan penguatan terhadap penelitian yang dilakukan saat ini. Perbedaan dalam penelitian ini dengan sebelumnya adalah fokus pengembangan inventori. Penelitian ini fokus terhadap proaktivitas siswa di sekolah menengah atas (SMA) berdasarkan kondisi yang dibutuhkan sehingga hasil penelitian ini mampu memberikan khasanah dalam pengembangan instrumen.

\section{Conclussion}

Berdasarkan hasil dan pembahasan dapat disimpulkan bahwa penelitian ini menghasilkan inventori proaktivitas siswa sekolah menengah atas (SMA) setelah melalui tahapan pengembangan inventori meliputi tahapan 1) Identifikasi tujuan ukur, 2) pembatasan domain ukur, 3) Operasional aspek, 4) Penulisan item, 5) Uji coba bahasa, 6) Field test, 7) Seleksi item, 8) Validasi konstrak, dan 9) Kompilasi Final. Pengembangan inventori menghasilkan 48 item yang valid sebesar 0,66 dan reliabilitas sebesar 0,887 . Proaktivitas yang dikembangkan dalam inventori meliputi tiga aspek yaitu memilih respon, inisiatif dan bertanggung jawab. Selain itu inventori di lengkapi dengan buku tes dan lembar jawaban.

\section{References}

Azwar, S. (2012). Penyusunan Skala Psikologis. Yogyakarta: Pustaka Pelajar.

Chaplin, C.P. (2006). Kamus Psikologi. Jakarta: Rajawali Press.

Covey, S.R. (2010). The Seven Habit of Highly Effective People. Terjemahan Lindon Saputra. Tangerang: Binarupa Aksara.

Heriansyah, M. (2017). Inventori Kepribadian Ideal Budaya Dayak Ngaju dalam Layanan Bimbingan dan Konseling. Jurnal Fokus Konseling, 3 (2), 175-184. http://doi.org/10.26638/jfk.318.2099 .

Marlina,E., Ahmad, M,A., Pandang, A (2015). Pengembangan Inventori Peminatan Karir (Ipk) Sebagai Alat Ukur Arah Pilih Karir Siswa. Jurnal Penelitian Tindakan Bimbingan dan Konseling. Vol. 1, No. 1, 59-64.

Susanto, E., \& Mudaim, M. (2017). Pengembangan Inventori MBTI Sebagai Alternatif Instrumen Pengukuran Tipe Kepribadian. Indonesian Journal of Educational Counseling, 1(1), 41-52. https://doi.org/10.30653/001.201711.5 
Yulinawati, I., Bariyyah, K., \& Permatasari, D. (2018). Pengembangan Inventori Stres Akademik Siswa Sekolah Menengah Pertama (SMP) Negeri Kota Malang. JKI (Jurnal Konseling Indonesia), 4(1), 30-35. https://doi.org/10.21067/jki.v4i1.2758. 